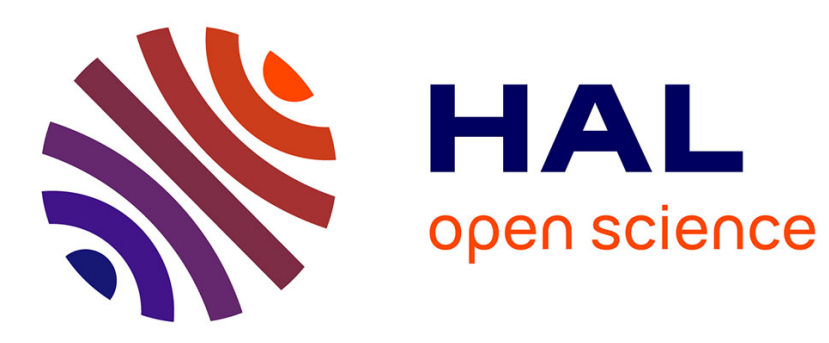

\title{
Toward a sustainable new product development approach based on industry 4.0 assets
}

Julie Bibaud-Alves, Bril El-Haouzi, Philippe Thomas, Vincent Boucinha

\section{To cite this version:}

Julie Bibaud-Alves, Bril El-Haouzi, Philippe Thomas, Vincent Boucinha. Toward a sustainable new product development approach based on industry 4.0 assets. 8th Workshop on Service Orientation in Holonic and Multi-agent Manufacturing, SOHOMA'18, Jun 2018, Bergamo, Italy. hal-01936069

\section{HAL Id: hal-01936069 \\ https://hal.science/hal-01936069}

Submitted on 27 Nov 2018

HAL is a multi-disciplinary open access archive for the deposit and dissemination of scientific research documents, whether they are published or not. The documents may come from teaching and research institutions in France or abroad, or from public or private research centers.
L'archive ouverte pluridisciplinaire HAL, est destinée au dépôt et à la diffusion de documents scientifiques de niveau recherche, publiés ou non, émanant des établissements d'enseignement et de recherche français ou étrangers, des laboratoires publics ou privés. 


\title{
Toward a sustainable New Product Development approach based on industry 4.0 assets
}

\author{
Julie Bibaud-Alves ${ }^{1,2,3}$, Hind Bril El-Haouzi ${ }^{1,2}$, Philippe Thomas ${ }^{1,2}$, and Vincent Bou- \\ cinha $^{3}$ \\ ${ }^{1}$ Université de Lorraine, CNRS, CRAN, F-88000 Epinal, France \\ julie.bibaud-alves4@etu.univ-lorraine.fr; \{hind.el-haouzi; philippe.thomas\}@univ- \\ lorraine.fr \\ ${ }^{3}$ Parisot Meubles, 15 avenue Jacques Parisot, 70800 Saint-Loup-sur-Semouse \\ \{jbibaud-alves; vboucinha\}@parisot.com
}

\begin{abstract}
The consumption society becomes more and more complex and challenging for companies. Therefore, industries must adapt their capacities to drive and continually improve their processes, resources and data management in a competitive environment. This paper aims to bring together and to link the concepts of new product development (NPD) process, digital transformation and sustainable development through a human centered approach. Organization, Process and Knowledge Management are the main NPD's classic critical focuses. The introduction of advanced technologies in products, in their development and in project portfolio management represents a huge opportunity to deal with their inherent complexity and to develop smart, connected products in a smart and connected industrial system. These evolutions should be considered within the framework of sustainable development, in order to design and produce better products in a better way regarding, among others, social, economic, environmental and ethic aspects.
\end{abstract}

Keywords: New Product Development, Sustainable Development, Digital Transformation

\section{INTRODUCTION}

Nowadays, companies have to design and produce more and more complex products, in a shorter time period, while reducing costs, in order to meet new customer's needs and to stay in adequacy with the organization's business goals. To succeed, the companies have to control their New Product Development (NPD) processes [1], the involved resources and the received, created, and broadcasted data. NPD is a central process that transform a market opportunity into a salable product. Several services are simultaneously involved (design, trading, technical and industrial studies, methods, purchasing and logistics departments) to choose the right concept, the right design, the adequate raw materials, components, assemblies, etc. The interdependences between all these 
activities, jobs and tools and the multiple iterations due to the creative nature of this process make it even more complex. To achieve the translation of the customer's needs into a manufacturable technical solution, the participation and involvement of all the departments is required, in a common way, and have to rely on a strong Knowledge Management System [2].

In many companies, the NDP process is not properly managed. Besides, $85 \%$ of the problems in the production process are known to be related to NPD process level decisions [3]. The process, the methods and the role of each person involved in the process are not clarified nor shared. The functional separation between the departments involved in the NPD process tend to worsen the situation. Modifications on current projects are more than frequent, leading to numerous iterations in the NPD process. Consequently, quality, cost and time objectives are not achieved [4]. Besides, the lack of clear and shared project management methods makes the portfolio and the NPD management even more difficult to synchronize with the organization's business goals. Best practices concerning project management and projects portfolio management have to be restored. Focus has to be set on organization (work organization, roles and coordination, training, skills and competencies), process (process management, activities and value, decision making factors and methods) and knowledge management (formalization and computerization) [5]. In many companies, the number of projects, the heterogeneity between them, the number of different skills, in and out of the company, increase the resources and data management complexity [4]. In order to make the right decisions, companies also have to be able to reuse and to analyze data. The introduction of advanced technologies can be a huge opportunity to deal with this complexity [6] [7]. It allows the design and production of smart connected products, which can interact with their environment and among each over and take decision. It can also automate low value-added activities.

The NPD process renewal is crucial point in the digital transformation of manufacturing companies. Before products became smart and connected, data was generated primarily by internal operations and through transactions across the value chain in the NPD process. In many companies, the data management system is unstructured, and the computer system is outdated. Technologies can help to computerize the NPD only if this one is clarified, shared and operational. The redesign of the NPD and its integration into the digital transformation should be developed within the framework of sustainable development in order to design and produce better products in a better way. The sustainable development is also a framework to organize the transition. It can help to develop a human centered approach, which can help to deal with the possible change resistance and take advantage of human capital skills.

This paper aims to bring together and to link the concepts of new product development process and of digital transformation, through a sustainable development approach. It is also an introduction to a $\mathrm{PhD}$ project with Parisot, a French octogenarian furniture manufacture, which seems to affirm its desire to significantly move towards new ways of working. Considering the crisis Parisot is facing, the obsolescence of its computer system and its management's difficulties, how can Parisot deal with this transformation (new objective-methods-tool's definition and implementation) while 
continuing to develop and produce goods? The first step is to define a global project, focused on research, to integrate sustainable development's concepts and tools into the NPD process methods and tools through the digital transformation of the whole company. In this article, NPD process definition and some classic methods and issues are presented. Then digital transformation is explained through a list of the different technologies used in the Industry 4.0 and how they can respond to the NPD issues. Finally, sustainable development is introduced as a new paradigm: a global framework to design and implement a digital NPD. The PhD project is approached in the conclusion as a potential pilot project.

\section{$2 \quad$ NPD process}

\subsection{DEFINITION}

In this part, NPD process definition and classic issues and methods are presented. It is important to highlight that NPD can be studied according to different and complementary perspectives (Fig. 1). In order to keep or win market shares, the company has to develop new products ( 1 in the Fig. 1). The complexity of the project management depends on the nature of the project, from a simple component change to an innovation project with a new industrial know-how.

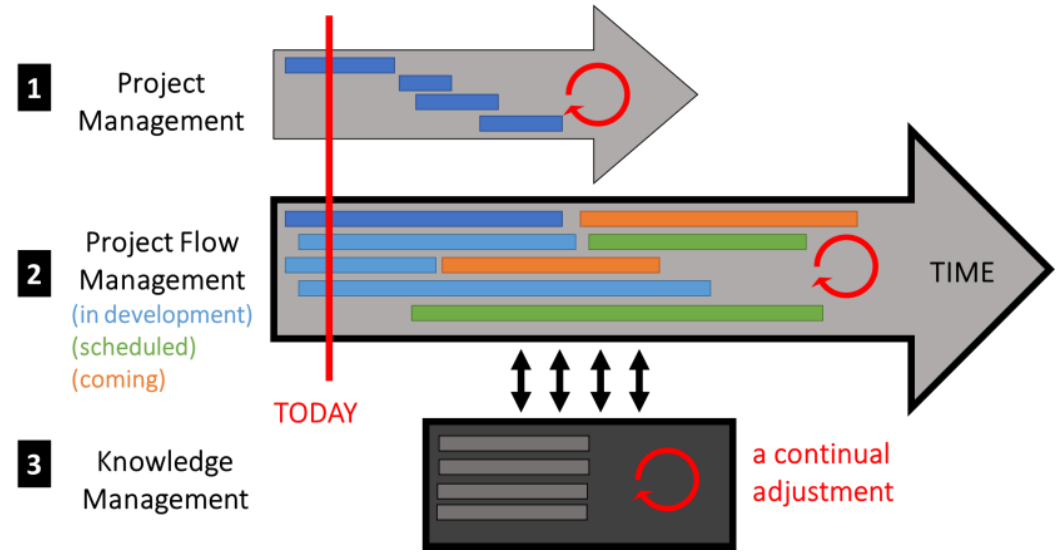

Fig. 1. NPD perspectives

Even if the NPD process modalities can vary according to companies' specificities and projects' maturity, the common steps are: Opportunity Identification; Opportunity Analysis; GO/NOGO; Idea Genesis; Idea Analyses; Idea Selection; GO/NOGO; Development; Testing; GO/NOGO; Launch.

The two first steps are often considered as predevelopment activities, during which, among others, source-of-supply, market research, customer value, business opportunities are detailed and assessed. It is also called the Fuzzy Front End and considered as a messy early phase of the NPD process. Most, if not all, of departments are of relevance 
to each of these phases. The departments' combined expertise enabled them to quickly draw a global specification up [8]. The coordination of all the departments is also crucial to take right decisions. The GO/NOGO phase can be associated to locks, controlled by a committee making decision thanks to tools such as multi-criteria analysis. To facilitate those phases and their coordination, a dynamic, efficient and structured information and data management system is required [9]. This system is a base, which enable to reuse and analyze the data, using KPI to assess the making decision process performance, and globally the NPD performance [10] [4]. Adopting a continuous improvement approach is essential.

Decision-making tools and management rules are also crucial, not only for projects, but for the whole NPD projects flow ( 2 in the Fig. 1). The challenge is increased by the number of project and their type variability. A formal Knowledge Management is required in order to bring efficiency into NPD process, decision-making process, their management and their continuous improvement (3 in Fig. 1) [2]. Knowledge cover both all the NPD experiences and the current industrial know-how. Indeed, the NPD is integrated to the whole company's system, which is divided in this article, in three parts: NPD, Strategy and Supply Chain / Machine Park (Fig. 2).

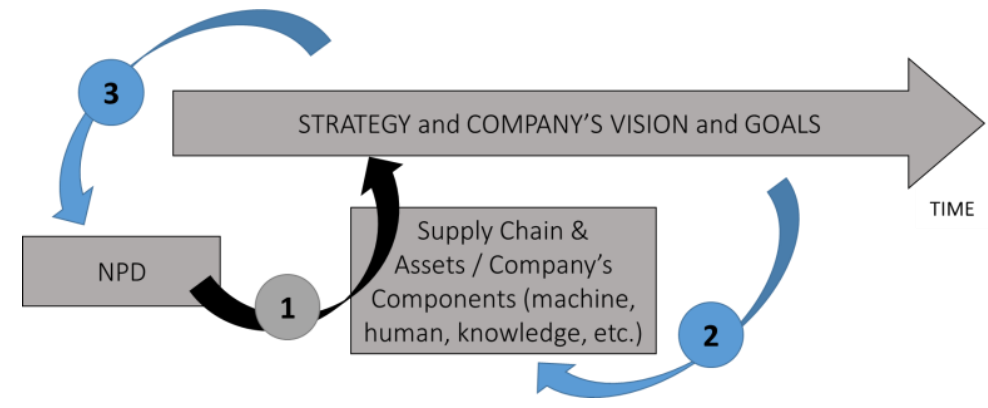

Fig. 2. NPD integrated in the company's system

In a functional system, NPD have to efficiently respond to the company's strategy, while making optimal use of the Supply Chain and Machine Park with a continuous improvement (short and medium term) and based a knowledge management system (1 in the Fig. 2) [11]. On long term level, companies have to anticipate the adaptation of their NPD, Supply Chains and Machine Parks (2 and 3 in the Fig. 2). Through this definition, in addition to the usual challenges of the human resource's management issues in such transdisciplinary business process, the complexity of the NPD management is easily perceived. The NPD's unmastered complexity is visible through various the issues and poor practices that can be find in many companies.

\subsection{PRINCIPAL ISSUES}

The principal issues find their origins in poor practices [5] (Fig. 3). The first dimension (Organization) concerns all the people involved in daily company's activities. The second dimension (Process) investigates how NPD is practically performed. The third 
dimension (Knowledge Management) is related to how companies create, share, represent and re-use their tacit and explicit knowledge. The figure below focuses on dimension 2 and 3.

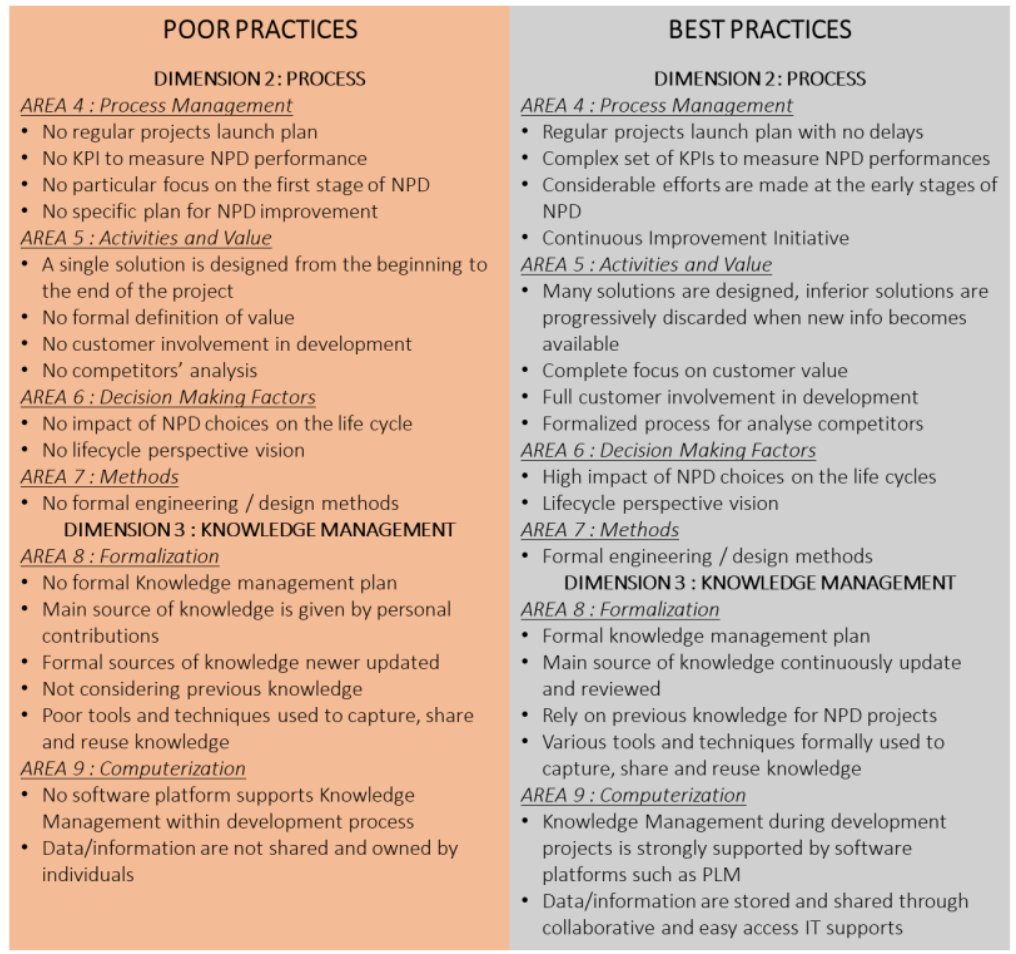

Fig. 3. NPD poor and best practices [5]

Issues also concern the NPD process position in the global company's system (Fig. 4). In the first case, NPD can develop new products adapted to the Supply Chain and the Machine Park, but that are not responding to the company's strategy. In the second case, NPD can develop new products responding to the company's strategy but impossible to produce with the current Supply Chain and Machine Park. In the third case, NPD can develop new products adapted to the strategy and to the Supply Chain and Machine Park, but for which the development stays inefficient because of the miscommunication between NPD office, Supply Chain and Machine Park. The global company's performance is reduced, and many quality issues appear [12]. 


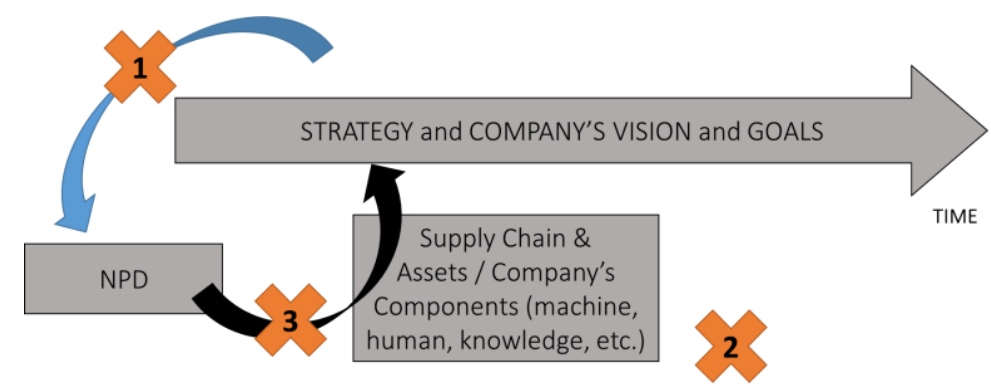

Fig. 4. Issues concerning NPD situation in the company's system

More research is needed about the most suitable practices to be used, considering the context [5]. Therefore, a $\mathrm{PhD}$ thesis project is a good opportunity to support a company in this challenge, while contributing to the research. Sustainable development and digital transformation will be two keys to find solutions, in order to implement best practices in the case study, for each NPD perspective, dimension and its integration into the global system [13].

\section{CASE STUDY THROUGH THE DIGITAL TRANSFORMATION}

\subsection{ANALYSIS of THE COMPANY STATE OF PLAY THROUGH THE NPD CONCEPTS AND THE DIGITAL TRANSFORMATION}

Parisot - Saint Loup's Unit - has been chosen, as a company, to be supported in its transition through a PhD thesis project. It's an octogenarian French furniture industry, which is facing a crisis primarily due to economic difficulties since 2012. This crisis went along with a reduction of its workforce, without transfer of knowledge or experience. It is one of the principal reasons why there are many poor practices, especially in the NPD. People have developed their own methods without sharing with each other's.

Beyond the above-mentioned poor practices (Fig. 3), Parisot's computer system is outdated, lacking a central data base. The informational flow is mainly paper-based, Email based, with no shared plan for the archives management, or is passing through meetings without agenda nor report. To stay competitive, Parisot needs to evolve and refresh its methods and tools using the Industry 4.0 opportunities. "Industry 4.0 " stands for "4th industrial revolution", based on Cyber-Physical Systems, following the 3rd one, which was based on electronics and IT usage for further automation of production. The term was created to emphasize the opportunities of digitizing and integrating all instances of value-adding system [14]. The fundament is the availability of relevant information everywhere they are needed and at any time, thanks to the involvement of all resources like humans, objects and systems. Those are integrated as dynamic, self- 
organized, real-time and autonomously optimized value-adding systems. The core technologies are [14]:

i. Engineering (e.g. digital and virtual engineering embedded software, smart materials)

ii. Manufacturing technologies and organization (e.g. self-directed manufacturing, responsive and adaptive manufacturing, additive manufacturing)

iii. Machines (e.g. intelligent sensors and actuators, remote and predictive maintenance, plug and produce integration and configuration)

iv. Smart capabilities (e.g. machine learning, multi-agent control, self-localization)

v. Robotics and human-robot-collaboration (e.g. mobile robots, soft robotics, data and sensor fusion)

vi. Production planning and control (e.g. intelligent production planning and control, manufacturing execution system integration, standardized interfaces)

vii. Logistics (e.g. autonomous logistics systems, track and trace concepts, geo-fencing)

viii. Work organization (e.g. flexible work organization, social business process management, competence management)

ix. Workplace design and assistance (e.g. human-machine interfacing, knowledge augmentation through Virtual / Augmented Reality, mobile devices, wearables, assistance and decision support systems)

x. $\quad$ Resource and energy efficiency (e.g. emission-neutral production, recycling management, urban manufacturing)

Those technologies are concerning different functions in the Enterprise, in the Information and Production dimensions and in the Business, Management and Human resources areas [14]:

1. Data collecting and processing (through sensors, RFID, storage and transmission, etc.)

2. Assistance systems (through Augmented Reality, human-machine-interfacing, decision support, etc.)

3. Networks and integration (through connected devices, cyber-physical systems, etc.)

4. Decentralization, service-orientation and flexibility (leading to new business models, flexibility and modular as well as scalable systems.)

5. Self-organization and autonomy (through control loops, self-configuration and optimization, machine learning, etc.)

As with the NPD practices, more research is needed about the most suitable technologies to be used depending on the context. The challenge is to find the best NPD practices coupled to the adapted technologies for a specific company, according to its needs and financial capacities. 


\section{2 $\quad$ Future directions}

The $\mathrm{PhD}$ thesis project has two main axis, both leading to one single objective: select and implement the adapted best practices and methods with the adequate advanced technologies system, considering Parisot's situation.

Concerning the best practices, some affirmations are selected from Fig. 3 and adapted to the different NPD perspectives. The research concerning each perspective (1/ Project management, 2/ NDP flow management, 3/ Knowledge Management; Fig. 1) for each dimension (2. Process, 3. Knowledge Management; Fig. 3) will be focused through five functional areas (1-Data Collection and processing, 2-Assistance systems, 3-Networks and integration, 4-Decentralization, service-orientation and flexibilities, 5Self-organization and autonomy).

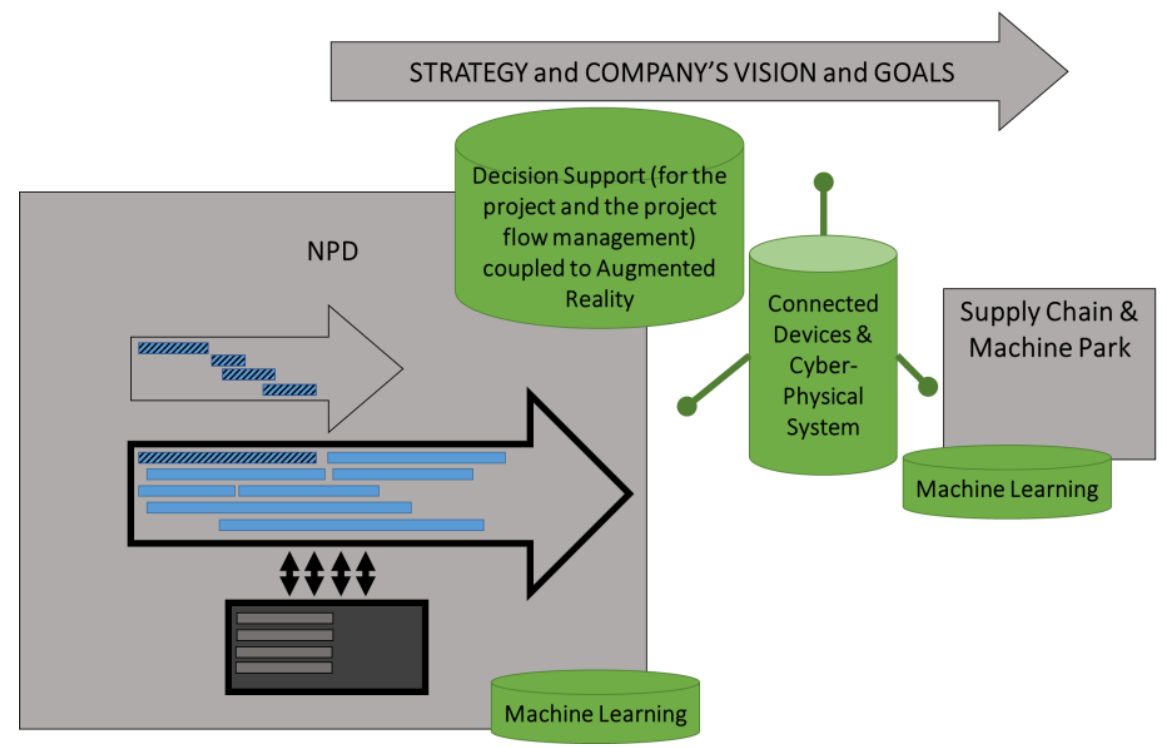

Fig. 5. Advanced Technologies integrated to the company's system

For example, thanks to a cyber-physical system with smart products based on the Internet of Things, NPD, Supply Chain and Machine Park can easily communicate and be synchronized for an optimal new product launch regarding to quality, cost and delays [15] (Fig. 5). All these processes can be recorded and analyzed [9] and, thanks to a machine learning system, can improve the knowledge management and continuous improvement. This system improves the decision support, perfecting the decision-making process concerning one project or the project portfolio management. The Augmented Reality can support the different actors involved, according to their respective tasks [7]. For example, it can help designers to prototype and the sales representatives to present and sell the products.

Making a system efficient is part of the Lean concept and, more broadly, of the sustainable development goals. Furthermore, through the introduction of advanced and 
disruptive technologies under the Industry 4.0 framework, Lean principles can be implemented in a more effective and consistent way [7], [16]. The Lean Product Development (LPD) and Green Product Development (GPD) belong to the same "currency", in which the implementation of both concepts calls for a systems perspective where the dimensions of process-people- tools/techniques are linked holistically [17].

Sustainable Development (SD) is also associated to the concept of "Transition". Concerning the case study, the $\mathrm{PhD}$ thesis project will support a huge transition for the company. For this reason, it is important to build and drive this project within a SD framework.

\section{SUSTAINABLE DEVELOPMENT AS A FRAMEWORK}

Often, people associate sustainable development to ecology or environment. But there is more than this dimension. "Environmental", "social" and "economic" dimensions are the most known. But regarding to the Chair of Eco-Advising's work - University of Quebec at Chicoutimi - "governance", "cultural", "ethical" and even "territorial" dimensions have to be added. Besides, based on the UNO's works, 17 goals have been defined. The NPD process in the furniture industry is particularly concerned by at least 3 out of these 17 goals:

- Goal 8: Promote sustained, inclusive and sustainable economic growth, full and productive employment and decent work for all.

- Goal 9: Build resilient infrastructure, promote inclusive and sustainable industrialization and foster innovation.

- Goal 12: Ensure sustainable consumption and production patterns.

Through the thesis project, SD will be integrated at different levels. This concept will be used to adapt best practices, advanced technologies system and their management to Parisot's needs, but also to elaborate and manage the transition action plan. This SD integration aims to respond to the three UNO's goals and to the company's goals (growth and performance). To achieve these, the work of the Chair on Eco-Advising will be used as a fundamental base. Among the policy instruments developed by this research chair, the Sustainable Development Analysis Grid (GADD) is a tool for systematic analysis that assesses the extent to which a policy, strategy, program or project promotes, among others, the improvement of human conditions [18]. It can be adapted to design and drive NPD best practices, for example by defining a complex set of KPIs to measure NPD performances.

The challenge lies in the implementation of the chosen methods. The process of implementation is the Transition (Fig. 6). In general, market perturbances put pressure on the company's system, which have to adapt its functioning, putting pressure on the operational activities. Without a plan, initiatives and projects start independently of each other. This provokes redundancy in the system and a lack of consistency, which therefore makes the system inefficient, even if people demonstrate willingness and determination. This leads to poor practices, disconnected from each other (Fig. 3). 
To be able to anticipate market perturbances, in a continual adjustment and improvement perspective, the company have to elaborate a plan. This transition action plan aims to bring the system to a target situation, which functions with best practices supported by advanced connected technologies in a Sustainable Development framework. This plan consists of three segments: Strategic, Tactical and Operational activities. This structuration helps to coordinate the various Initiatives and Projects through the company's system in order to make the transition more efficient. From the target situation, Strategic activities are defined to achieve the target. To achieve those Strategic activities, these are subdivided into Tactical activities. Those are also subdivided into Operational activities.

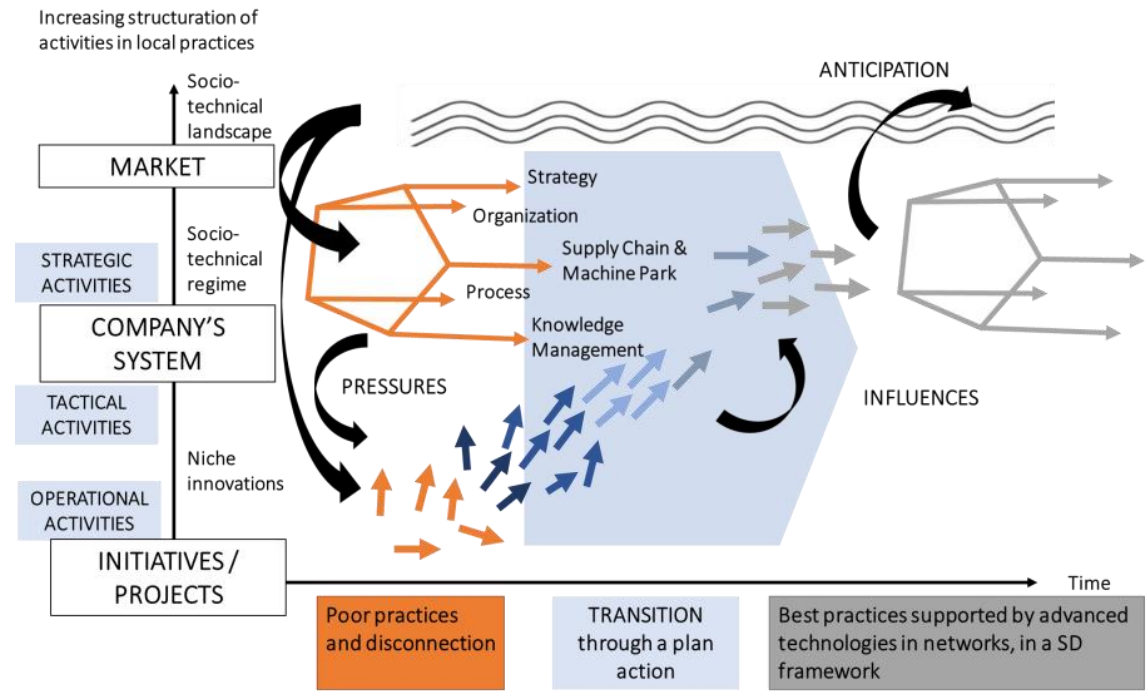

Fig. 6. Transition Management (inspired by [19])

The target situation and the Strategy have to be elaborated by the management committee. Concerning the case study, the master thesis project aims to help this committee finding the right pentagon composed by the five dimensions explained through this article (Strategy, Supply Chain and Machine Park, Organization, Process, and Knowledge Management) and the adapted advanced technologies to support the new system. It also aims to elaborate the transition action plan, concerning the Tactical and Operational Activities. Those activities could take the form of workshops, which enable a humancentered approach, focusing on the social, cultural and ethics SD dimensions.

\section{CONCLUSIONS AND OUTLOOKS}

NPD has a central position between the company's strategy and the Supply Chain and Machine Park. In the Industry 4.0 context, advanced technologies allow to link those three parts through a cyber-physical system with smart connected products from the fuzzy early stage of the development (Opportunity Identification) to the launch or 
even to the streamlining of the range of products, thanks a dynamic updated knowledge management system. The quest for efficiency and effectiveness of the global system is carried out in a global sustainable development framework, which help to better grasp the complexity.

Various models have been developed but the current challenge is their adaptation and implantation in companies. The $\mathrm{PhD}$ thesis project is an opportunity to work on this through a concrete case study. Parisot is today ready to change and needs to be supported through its transition. Here, the future step will consist in defining the adapted methods and an action plan to drive Parisot's transition.

\section{REFERENCES}

1. Cooper R.G, Winning at New Products, 3rd ed. Publishing Company, (2001)

2. N. Belbaly, E. Houzé, Etude empirique de l'effet de la création de connaissances sur le processus de développement de nouveaux produits, XVIème ConférenceInternationale de Management Stratégique (2007)

3. Schomberger R.J., Japanese manufacturing techniques: nine hidden lessons in simplicity. Macmillian USA (1982)

4. M. Rossi, E. Kerga, M. Taisch, S. Terzi, Engineering and Design Best Practices in New Product Development: an Empirical Research, 24 ${ }^{\text {th }}$ CIRP Design Conference (2014)

5. Y.M. Tai, Effects of product lifecycle management systems on new product development performance, Journal of Engineering and Technology Management, vol. 46, pp. 67-83. Elsevier (2017)

6. R.Y. Zhong, X. Xu, E. Klotz, S.T. Newman, Intelligent Manufacturing in the Context of Industry 4.0: A Review, Engineering, vol. 3, pp. 616-630. Elsevier (2017)

7. M.L. Nunes, A.C. Pereira, A.C. Alves, Smart products development approaches for Industry 4.0, Manufacturing Engineering Society International Conference, MESIC Spain, (2017)

8. E. Genç, C.A. Di Benedetto, Cross-functional integration in the sustainable new product development process: The role of the environmental specialist, Industrial Marketing Management, vol. 50, pp. 150-161. Elsevier (2015)

9. W. Scheidel, I. Mozgova, R. Lachmayer, Product Data Management in the Context of Industry 4.0, 59th Ilmenau Scientific Colloquium, (2017)

10. O.K. Tan, A. Rasli, Prediction of New Product Development (NPD) Performance in Research and Development (R\&D) Company, 3rd International Conference on Advanced Management Science, vol. 19, pp. 192-200. Elsevier (2011)

11. Z.A.Afrouzy, S.H.Nasseri, I.Mahdavi, A genetic algorithm for supply chain configuration with new product development, Computers \& Industrial Engineering, vol. 101, pp. 440-454. Elsevier (2016)

12. Z.A.Afrouzy, S.H.Nasseri, I.Mahdavi, M.M. Paydar, A fuzzy stochastic multi-objective optimization model to configure a supply chain considering new product development, Applied Mathematical Modelling, vol. 40, pp. 7545-7570. Elsevier (2016)

13. H. Gmelin, S. Seuring, Achieving sustainable new product development by integrating product life-cycle management capabilities, Int. J.ProductionEconomics, vol. 154, pp. 166177. Elsevier (2014)

14. R. Neugebauer, S. Hippmann, M. Leis, M. Landherr, Industrie 4.0 - From the perspective of applied research, 49th CIRP Conference on Manufacturing Systems, (2016) 
15. K. Santos, E. Loures, F. Piechnicki, O. Canciglieri, Opportunities Assessment of Product Development Process in Industry 4.0, 27th International Conference on Flexible Automation and Intelligent Manufacturing, (2017)

16. E. Rauch, P. Dallasega, D.T. Matt, The way from Lean Product Development (LPD) to Smart Product Development (SPD), the 26th CIRP Design Conference, Procedia CIRP, vol. 50, pp. $26-31$ (2016)

17. Johansson, Glenn, Sundin, Erik. Lean and green product development : two sidesof the same coin ?, Journal of Cleaner Production, vol. 85, pp. 104-121, (2014)

18. Villeneuve, C., Riffon, O. and Tremblay, D., How is sustainable development analyzed? User Guide for the Sustainable Development Analysis Grid. Département des sciences fondamentales, Université du Québec à Chicoutimi, in partnership with the OIF/IFDD, (2016)

19. J. Grin, J. Rotmans, J. Schot, Transitions to Sustainable Development: New Directions in the Study of Long Term Transformative Change, (2011) 